\title{
A possible case of exfoliative dermatitis due to ibuprofen in an Eleven- month-old infant
}

\author{
Sudipto Chatterjee ${ }^{1}$, R. Vijendra ${ }^{2 *}$, Yashoda H. T. ${ }^{3}$, Neil M. Salian ${ }^{4}$
}

${ }^{1}$ Tutor, ${ }^{2}$ Department of Pharmacology, ${ }^{3}$ Department of Pediatrics, ${ }^{4}$ Student,

Kempegowda Institute of Medical Sciences, Bangalore, Karnataka, India

Received: 23 September 2018 Accepted: 22 October 2018

\section{*Correspondence to: \\ Dr. R. Vijendra, \\ Email: vijendra_ramaiah@ yahoo.co.in}

Copyright: (C) the author(s), publisher and licensee Medip Academy. This is an openaccess article distributed under the terms of the Creative Commons Attribution NonCommercial License, which permits unrestricted noncommercial use, distribution, and reproduction in any medium, provided the original work is properly cited.

\begin{abstract}
Ibuprofen is a NSAID belonging to the class of propionic acid derivatives which is widely used for its analgesic, antipyretic and anti-inflammatory action. Wellknown adverse effects of ibuprofen include gastric irritability leading to nausea and vomiting as well as allergic manifestations such as urticaria and skin rashes. Severe ADRs include renal papillary necrosis, SJS/TEN, and thrombotic events leading to myocardial infarction and stroke. Authors present a case of exfoliative dermatitis in an 11-month-old infant possibly due to ibuprofen. An 11-month-old infant was prescribed syrup ibuprofen by a local medical practitioner for unclear reasons. Three days after ibuprofen therapy, the infant developed erythematous, crusting exfoliative lesions predominantly over the face with a few lesions over the lower abdomen. Subsequently, the infant was admitted to Kempegowda Institute of Medical Sciences and Research Center Hospital, Bangalore. A diagnosis of drug-induced exfoliative dermatitis was made after ruling out other causes. Treatment was initiated with intravenous and topical dexamethasone along with saline compressions and amoxicillin + clavulanic acid for secondary bacterial infection as well as topical emollient cream applied over the affected areas. The lesions improved significantly with the above management and the infant recovered enough to be discharged from the hospital after 3 days. The reaction was assessed to be "possible" as per Naranjo and WHO-UMC causality assessment scales, "moderately severe" on modified Hartwig's severity assessment scale and "not preventable" according to Schumock and Thornton criteria. Severe and serious reactions such as exfoliative dermatitis can be caused by commonly used drugs like ibuprofen.
\end{abstract}

Keywords: Adverse drug reaction, Exfoliative dermatitis, Ibuprofen, NSAIDs

\section{INTRODUCTION}

Ibuprofen is a commonly used NSAID mainly for its analgesic, antipyretic and anti-inflammatory actions. It is indicated to be used in adults and pediatric patients $\geq 6$ months for the management of mild to moderate pain and the management of moderate to severe pain as an adjunct to opioid analgesics as well as for reduction of fever. It is administered at a dose of $10 \mathrm{mg} / \mathrm{kg}$ for analgesia and fever in patients aged between 6 months to 12 years. Ibuprofen is also available for use as fixed-dose combinations with paracetamol, pseudoephedrine, glucosamine and chlorzoxazone. ${ }^{1}$
Adverse effects of ibuprofen are similar to the drugs belonging to the class of NSAIDs. They include cardiovascular thrombotic events; gastrointestinal bleeding, ulceration, and perforation; hepatotoxicity; hypertension; heart failure and edema; renal toxicity and hyperkalemia; anaphylactic and anaphylactoid reactions; exacerbation of asthma related to aspirin sensitivity; serious skin reactions; premature closure of fetal ductus arteriosus; hematological toxicity; and masking of inflammation and fever. ${ }^{2}$

Majority of the adverse effects of ibuprofen are due to nonspecific inhibition of cyclooxygenase (COX) enzyme 
leading to suppression in the synthesis of prostaglandins. The important adverse effects due to COX inhibition include gastrointestinal (GI) irritation by suppressing mucus production in the stomach and renal damage (acute tubular necrosis). Serious gastrointestinal adverse events include GI bleeding, ulceration, and perforation of stomach or intestines. Ibuprofen is also well known to cause hypersensitivity reactions including skin rashes. Severe adverse drug reactions (ADRs) include renal papillary necrosis, Stevens-Johnson syndrome (SJS)/toxic epidermal necrolysis (TEN) and thrombotic events leading to myocardial infarction and stroke. The incidence of cutaneous ADRs due to ibuprofen is estimated to be $5 \%$. $^{3}$

Exfoliative dermatitis (ED) is the result of increased epidermal turnover rate and the time for cells to mature and travel through the epidermis is decreased. The increased loss of epidermis results in severe scaling and shedding. ${ }^{4}$

The common etiologies for ED include infections, drug reactions, malignancies and preexisting dermatoses (psoriasis, atopic dermatitis, seborrheic dermatitis, and contact dermatitis). ${ }^{5}$ Drugs which are well-known to cause ED include paracetamol, barbiturates, anti-tubercular drugs (isoniazid, rifampicin, streptomycin, paraaminosalicylic acid, ethambutol), antiepileptic drugs (phenytoin) and antimicrobial agents (tetracycline, vancomycin, penicillins, minocycline). ${ }^{6}$ Drug-induced ED usually occurs within a few days to several weeks after drug exposure. Erythema multiforme (EM) major / minor, SJS and TEN are the main types of clinical presentations of drug-induced ED.

Drug-induced ED is mediated by deposition of immune complexes (mostly IgM-bound complexes) in the superficial microvasculature of skin and mucous membranes, principally mediated by the T cells. A key role in the pathogenesis of ED is played by CD8+ lymphocytes and NK cells. ${ }^{4}$

\section{CASE REPORT}

An 11-month-old infant was prescribed ibuprofen syrup by a local medical practitioner for unclear reasons. Three days after ibuprofen therapy, the infant developed erythematous, crusting exfoliative lesions predominantly over the face with a few lesions over the lower abdomen. Subsequently, the infant was admitted to Kempegowda Institute of Medical Sciences and Research Center Hospital, Bangalore. A diagnosis of drug-induced exfoliative dermatitis was made after ruling out other causes.

Laboratory investigations are within normal limits except mild leukocytosis. There was no past history of ibuprofen use. There was no past history of any drug allergy.

Treatment was initiated with intravenous and topical dexamethasone along with saline compressions and amoxicillin + clavulanic acid for secondary bacterial infection. Topical emollient cream was applied over affected areas also. The lesions improved significantly with the above management and the infant was discharged after 3 days.

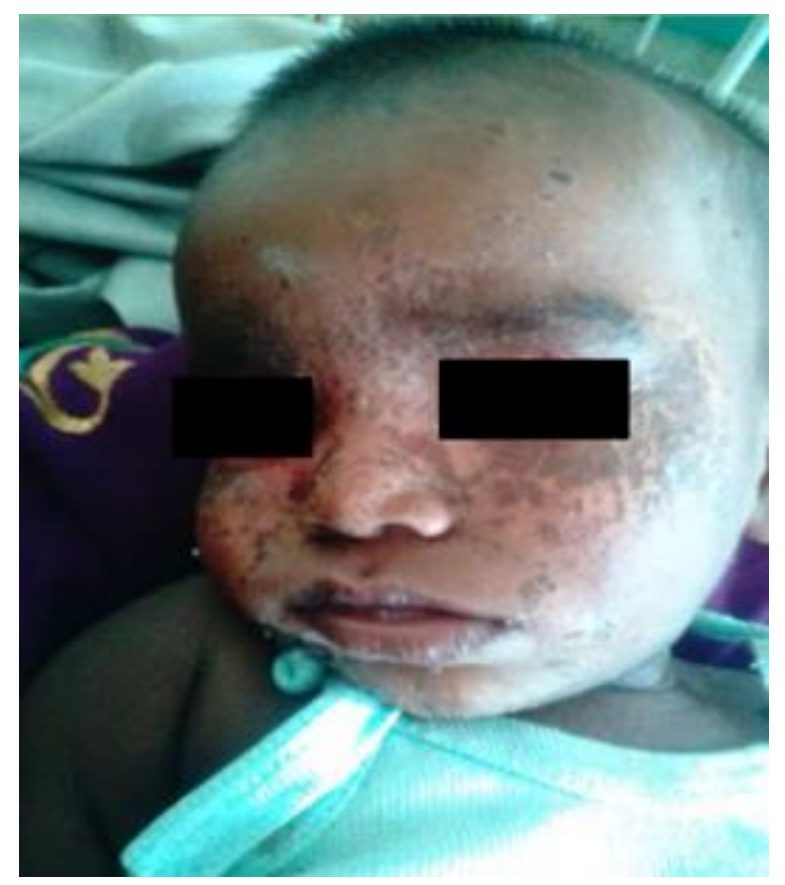

Figure 1: Resolving lesions of exfoliative dermatitis 3 days after drug reaction.

\section{DISCUSSION}

The present case was subjected to causality assessment using Naranjo's criteria (Table 1) as well as the WHOUMC causality scale. ${ }^{7}$ Assessment with Naranjo's scale indicated a total score of 3 indicating "a possible" causality, which was also the case when the case was subjected to WHO-UMC causality assessment. The severity of the ADR as assessed by the modified Hartwig's severity assessment scale points to level 4 severity indicating it to be a "moderately severe" adverse drug reaction. ${ }^{8}$ The ADR was assessed to be "not preventable" using the Schumock and Thornton preventability scale. ${ }^{9}$

Ibuprofen is a commonly prescribed medication for the management of pain and inflammation. ${ }^{10}$ In children, ibuprofen is preferred over paracetamol for management of pain. ${ }^{11}$ The most frequent adverse reactions with ibuprofen involve the gastrointestinal, renal, skin and the respiratory system.

Drug induced ED due to ibuprofen can range from erythema multiforme minor to TEN leading to significant morbidity and even mortality. This infant represents a possible case of ibuprofen-induced exfoliative dermatitis. Prescribers should be mindful of adverse drug reactions such as exfoliative dermatitis as a result of ibuprofen intake, particularly in children. 
Table 1: Naranjo adverse drug reaction Probability Scale.

\begin{tabular}{|lllll|}
\hline Questions & Yes & No & Do not know & Score \\
\hline Are there previous conclusive reports on this reaction? & +1 & 0 & 0 & 1 \\
\hline Did the adverse event appear after the suspected drug was administered? & +2 & -1 & 0 & 2 \\
\hline $\begin{array}{l}\text { Did the adverse reaction improve when the drug was discontinued or a } \\
\text { specific antagonist was administered? }\end{array}$ & +1 & 0 & 0 & 1 \\
\hline Did the adverse event reappear when the drug was re-administered? & +2 & -1 & 0 & 0 \\
\hline $\begin{array}{l}\text { Are there alternative causes (other than the drug) that could on their own have } \\
\text { caused the reaction? }\end{array}$ & -1 & +2 & 0 & -1 \\
\hline Did the reaction reappear when a placebo was given? & -1 & +1 & 0 & 0 \\
\hline $\begin{array}{l}\text { Was the drug detected in blood (or other fluids) in concentrations known to be } \\
\text { toxic? }\end{array}$ & +1 & 0 & 0 & 0 \\
\hline $\begin{array}{l}\text { Was the reaction more severe when the dose was increased or less severe } \\
\text { when the dose was decreased? }\end{array}$ & +1 & 0 & 0 & 0 \\
\hline $\begin{array}{l}\text { Did the patient have a similar reaction to the same or similar drugs in any } \\
\text { previous exposure? }\end{array}$ & +1 & 0 & 0 & 0 \\
\hline Was the adverse event confirmed by any objective evidence? & +1 & 0 & 0 & \\
\hline Total score & & & 0 \\
\hline Interpretation: $\geq 9=$ Definite ADR; $5-8=$ Probable ADR; $1-4=$ Possible ADR; 0=Doubtful ADR & & \\
\hline
\end{tabular}

\section{CONCLUSION}

Severe and serious reactions such as exfoliative dermatitis can be caused by commonly used drugs like ibuprofen and prescribers should be aware of such adverse effect.

Funding: No funding sources

Conflict of interest: None declared

Ethical approval: The study was approved by the Institutional Ethics Committee of KIMS, Bangalore, India

\section{REFERENCES}

1. Fixed dose combinations approved by DCG(I). Available at:

http://cdsco.nic.in/writereaddata/Approved\%20FDC \%20list\%20till\%2012th\%20July\%202018.pdf.

Accessed 11 September 2018.

2. De Martino M, Chiarugi A, Boner A, Montini G, de' Angelis GL. Working Towards an Appropriate Use of Ibuprofen in Children: An Evidence-Based Appraisal. Drugs. 2017;77(12):1295-311.

3. Patel TK, Thakkar SH, Sharma D. Cutaneous adverse drug reactions in Indian population: A systematic review. Indian Dermatol Online J. 2014;5:S76-86.

4. Yacoub MR. Drug induced exfoliative dermatitis: state of the art. Clin Mol Allergy. 2016 Aug 22;14:9.
5. Karakayli G, Beckham G, Orengo T. Exfoliative dermatitis. Am Fam Physician. 1999;59:625-30.

6. Sehgal VN, Srivastava G, Sardana K. Erythroderma/exfoliative dermatitis: a synopsis. Int J Dermatol. 2004 Jan;43(1):39-47.

7. Naranjo CA, Busto U, Sellers EM, Sandor P, Ruiz I, Roberts EA, et al. A method for estimating the probability of adverse drug reactions. Clin Pharmacol Ther. 1981 Aug;30(2):239-45.

8. Hartwig SC, Siegel J, Schneider PJ. Preventability and severity assessment in reporting adverse drug reactions. Am J Hosp Pharm. 1992;49(9):2229-32.

9. Schumock GT, Thornton JP. Focusing on the preventability of adverse drug reactions. Hosp Pharm. 1992;27(6):538.

10. Bushra R, Aslam N. An Overview of Clinical Pharmacology of Ibuprofen. Oma Med J. 2010;25(3):155-661.

11. Kanabar DJ. A clinical and safety review of paracetamol and ibuprofen in children. Inflammopharmacology. 2017;25(1):1-9.

Cite this article as: Chatterjee $\mathrm{S}$, Vijendra $\mathrm{R}$, Yashoda HT, Salian NM. A possible case of exfoliative dermatitis due to ibuprofen in an Elevenmonth-old infant. Int J Basic Clin Pharmacol 2018;7:2462-4. 